\title{
The Technical and Design Characteristics of Traditional Natural Lighting Methods in Islamic Architecture
}

\author{
${ }^{1}$ Mutasem Azmi Al-karablieh, ${ }^{2}$ Mosab Mahmoud AL-Qudah, ${ }^{3}$ Jehad Hasan ALameri, \\ ${ }^{4}$ Ibrahim Ahmad AL-Khatib, ${ }^{5}$ Haifaa Ahmad Bani Ismail, ${ }^{6}$ Diran John Malatjalian \\ 1, 2, 3,4,5,6 The University of Jordan
}

\begin{abstract}
Lighting is an important element to carry out life activities within architectural spaces. Every life activity depends on the level of lighting in the vacuum. This level varies according to the activities and the size of the interior space. The pursuit of lighting spaces in a way that is compatible with the functional and aesthetic dimensions in the interior Islamic design is one of the controversies worthy of research and study, as it is possible to establish patterns of lighting in the modern interior design follow the principles of lighting used in Islamic architecture, where patterns of natural and industrial lighting have both functional and aesthetic objectives. The importance of this research is to study the effect of traditional lighting patterns used in Islamic architecture on the lighting of internal spaces, and how to influence the formation and structure of modern and contemporary spaces by studying the impact of these patterns in controlling the quantity and efficiency of natural and industrial lighting in the vacuum through an analytical study of the performance of these patterns.
\end{abstract}

Keywords: Architecture, Tourism, Interior Design, Traditional Lighting, History of Islamic Art

DOI: $10.7176 / \mathrm{JTHS} / 41-07$

Publication date:May 31st 2019

\section{Introduction}

In the Islamic arts, the works related to the crafts have been spread and developed through the development of traditional architectural styles and models which have become distinguished from other arts. The architecture flourished from the Umayyad period in the Levant, in Damascus it was manifested through the homes of its beautiful and innovative architecture, "The Damascus artisans unleashed their imagination by introducing new methods and styles in the intricate and intertwined decoration in their contrast"1. In addition to the most important functional and aesthetic issues complementary to the interior design is the availability of sources of good and comfortable lighting suited to the space and architectural vacuum and integrate with the prevailing architecture and harmony with it, the formation of architectural as an architectural block affects the permeability and perception of light in the inner space, and these patterns have confirmed their coherence and cohesion with the architectural mass to find rhythm and harmony between the inside and outside, "Space is the first and last purpose of the construction work, each building begins with the design first, ending with the allocation of space in the vacuum, which is of course the reason for the existence of this building, each building necessarily arises for its occupant."2

The emergence of new patterns in Islamic art has shown a skill and innovation in the Islamic architecture in the manufacture of light and its formation in the vacuum with an abstract decorative tendency that

\footnotetext{
${ }^{1}$ Melnik, V. (2008). The treasures of Damascene architecture, Vol.1, pp. 59-60, Dar Al Sharq for Printing and Publishing, Damascus

${ }^{2}$ Al-Farouqi, I. (1983), Islam and Architecture, Contemporary Muslim Magazine, Vol.34, p. 90, Beirut
} 
leads to contemplation of the aesthetic rhythms of light through its infiltration of hollow decorative openings and reflections in the space on the surrounding walls.

There is no doubt the emergence of some traditional patterns ${ }^{3}$ in Islamic architecture, which clung to one of the most important principles of Islamic art, which is the principle of unity as one of the most important characteristics of the architectural configuration of the vacuum and the group of spaces related to the construction formative to add to that the view of Islamic architecture to adapt to the climatic patterns and natural or other inherited, these patterns in Islamic architecture are prominent features that reflect the traditional heritage of Islamic architecture and have served to highlight the features and attributes of Islamic architecture over the centuries. "The unity of architecture has involved the interdependence of elements of architecture and the interrelationship between the functions and objectives of space" ${ }^{\text {"4 }}$

\section{Research problem}

Light in interior design is an important element in carrying out life activities within architectural spaces and exterior spaces, a good architectural design requires the need to achieve visual comfort in all areas and spaces, it also depends on every life activity, the office room requires a level of lighting is different than the level required to sit in the living room or reception, Therefore, the problem of achieving spaces that are lit in a way that is compatible with the functional and aesthetic dimensions in the interior design is one of the arguments that deserves to be studied in terms of the effect of lighting in the interior design. Hence, the problem of research is to study and analyze the traditional lighting methods in Islamic architecture and their suitability in achieving compatibility and harmony in the design and internal vacuum.

\section{Research goals}

The importance of the study is to demonstrate the importance of traditional lighting patterns in Islamic interior design and their relationship in the internal space, it also aims to:

1. The study of the relationship between lighting in the interior spaces in Islamic architecture, how to adapt them to the internal spaces, through the analysis and extrapolation of the lighting methods used in Islamic architecture and its relationship to lighting the internal space and the foundation of the concept of Islamic architecture in the tourist concept represented by its architectural form.

2. Have traditional lighting patterns in Islamic interior design achieved quality in terms of efficiency and effectiveness?

3. To reach the relationship of light with the inner vacuum by analyzing different samples of traditional natural and industrial lighting patterns of Islamic architecture.

4. Deepening the concept in the tourist or visitor to these places in the role played by architecture in highlighting the light.

\footnotetext{
${ }^{3}$ Tradition "is the name given to what is transmitted culturally, especially that which is determined over long periods of time, and tradition in its broad sense, without generalization or allocation, that is the powerful mass that consists of what we inherit from the oldest of the actions, trends, systems, (1972) Evolution in the Arts, translated by Mohammed Ali Abu Durra et al., 2, p. 42, i., Egyptian Book Authority, Cairo.

${ }^{4}$ Nasr, H. (2004). Principles of Islamic Architecture and Contemporary Urban Problems, p. 7 Articles in Islamic Arts, Jordan
} 


\section{Research Methodology}

The research is based on the selection of different samples of natural and industrial light patterns from Islamic architecture to be a research area to determine their agreement and compatibility with the requirements of good lighting in the internal space and to determine their aesthetic and functional characteristics.

\section{Traditional natural lighting patterns}

The architecture, like other arts, and the light plays a prominent role in showing its characteristics and elements. The light has emerged in Islam in its aesthetic, functional and spiritual dimensions, it is noticed in the Islamic buildings mixing the internal and external spaces, and this is achieved by the establishment of windows and the open lobby or the courtyard, which encircles the interior area of the limits of the building, Muslims contributed actively to the design of lighting in their buildings, starting from the use of courtyards and marshrabiyas and hollow openings on high ceilings and openings, the Muslim architect took care of two things to light his building during the day. The first: the environmental conditions associated with climate, and second: social conditions, linked to the principle of privacy. ${ }^{5}$ In fact, these buildings share the same climatic features. The natural light that engulfs the entire building is the necessary and fundamental link between the interior space and the outer space, the light appears in Islamic art, interspersed with domes and windows in infinite rhythm and repetition. Similar units in size, color and organization of units are represented in successive frames that move in artistic rhythms, where the repetition emphasizes the harmony and symmetry and concentration and highlights the elements of art and hence the concept of abstraction differed when the Muslim artist from other arts where he expressed the visual reality and tangible beyond the direct visual, in a philosophical and contemplative view, the light was used to send out spiritual reflections that crept into the inner space of Islamic architecture. See Figures $1+2+3$.

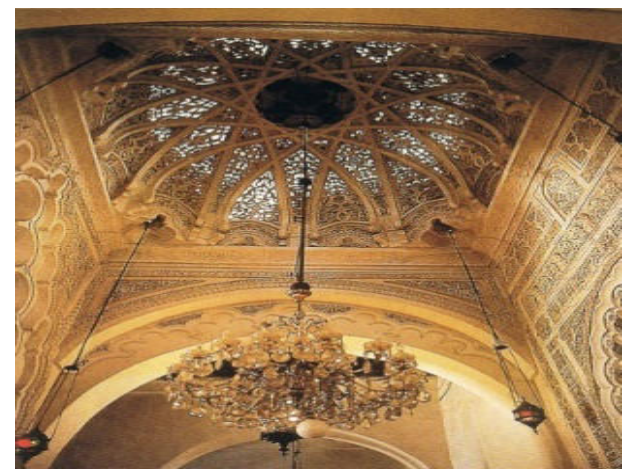

Figure (1): The Dome of the Great Mosque in Tlemcen, which is a group of cross arcs and interspersed with light from the decoration of the decorative light from the top to the bottom with decorative beams

\footnotetext{
${ }^{5}$ Ghaleb, A. (1988). Encyclopedia of Islamic Architecture, Vol,1., p. 57, Arabic Printing Press, Beirut.
} 


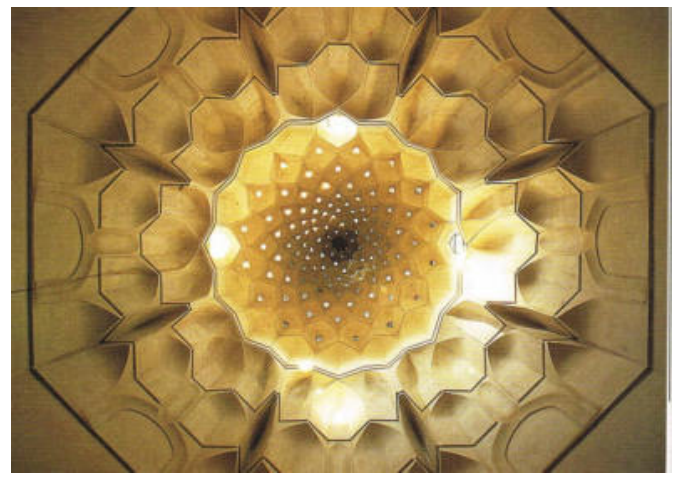

Figure (2): the shrine of Zubaidah in Baghdad, Dome of the Hornet with openings and windows for lighting

In the Andalusian mosques, the arches were built on top of each other, with a deliberate engineering distribution that increases the openings, diversifies, shapes and helps to make the ceilings, the higher the arches and the more resistant arches, the air is faster and the light is more widespread.

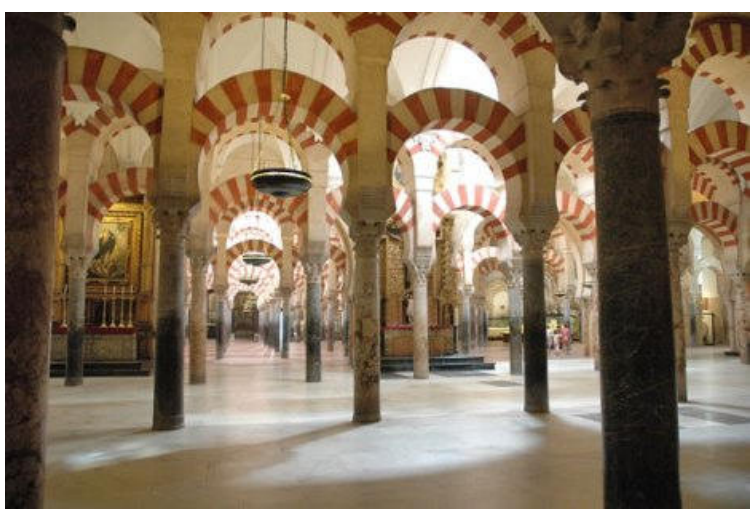

Figure (3): The Mosque of Cordoba: These arches from the Mosque of Cordoba show the use of brackets on two levels, which made the light more widespread in the inner space

In the Dome of the Rock, a unique type was used by the Muslim artist to benefit from natural lighting, where the mosaic appears and covers some interior parts, in the form of "small cubes of colored glass, noncolored, and transparent, and small cubes of shells and all are installed on a layer of cement in a perfect horizontal position, Except for cubes of golden or silver color, they are placed in a little tilt to reflect the light, ${ }^{6}$ "The use of jewelry forms made of shells and precious stones and implanted in the forms of plants in the Dome of the Rock, ${ }^{7}$ it has given a brilliant luster contributed to the spread of light in the interior space, and this shows that the choice of material in the arts and architecture of Islam had a functional and aesthetic purpose in highlighting the light and employment, in the Islamic decades, a kind of structural rhythm emerges from the repetition of architectural contracts, sequence and gradation, which gives a structured vacuum to the mass and void through the light falling on these curves, as darkness and light determine and confirm its meaning (see figure 4).

\footnotetext{
${ }^{6}$ Zaki, H. (1956). Atlas of Decorative Arts and Islamic Painting, Vol, I., p. 561, Cairo University Press, Cairo.
}

${ }^{7}$ Saqr, I. (2003). Islamic Arts, Vol, 1., p. 220, Dar Majdalawi, Amman. 


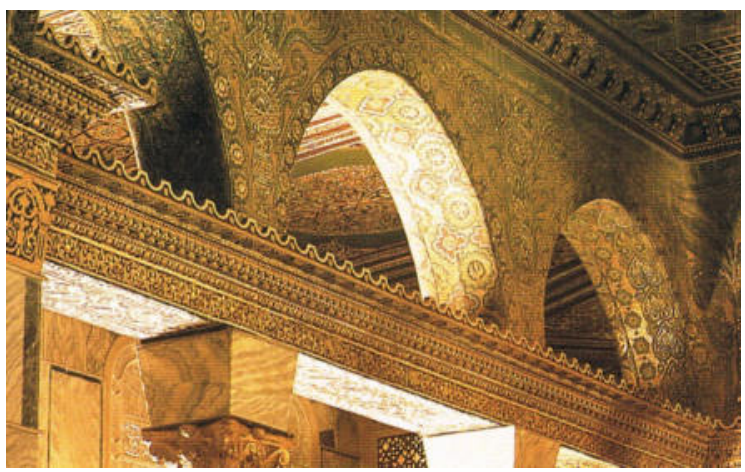

Figure (4): A group of arches (Dome of the Rock), where the light shrouds the area with the help of arches and gives it an aesthetic dimension and helps spread light

The presence of paved lanes in the middle squares has helped to reduce solar radiation to the interior and at the same time to have adequate and sufficient lighting in the interior spaces, capes helped spread light more widely in spaces. In some Islamic buildings, the use of contracts and domes derived from daylight was used to distribute light within the vacuum.

When the light bursts into the space and the architectural vacuum, it is bright and alive. By dealing with the natural and industrial light now, the jellyfish and the domes of the domes are moved to the heart of the radiant universe. The drops of light come upon the folds of the ornamentation and the horns, see Figure 5.

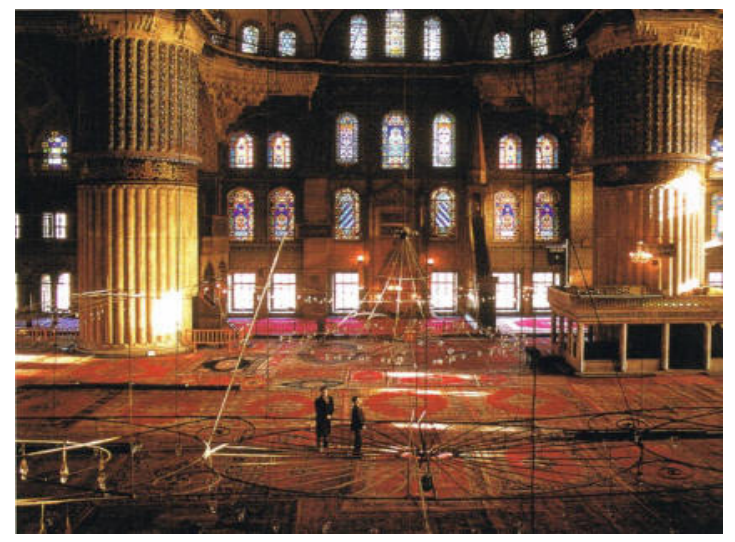

Figure (5): The Sultan Ahmad Mosque in Istanbul. The natural lighting and the use of decorative patterns gave an aesthetic dimension to the industrial lighting through the use of suspended jellyfish which gave light at lower levels

Dealing with light in general in the Islamic tradition through two methods (simplicity and dumping), in examples (5), dumping light from the surrounding areas on the decorations to increase their light up to the peak of the dome, see Figure (6). 


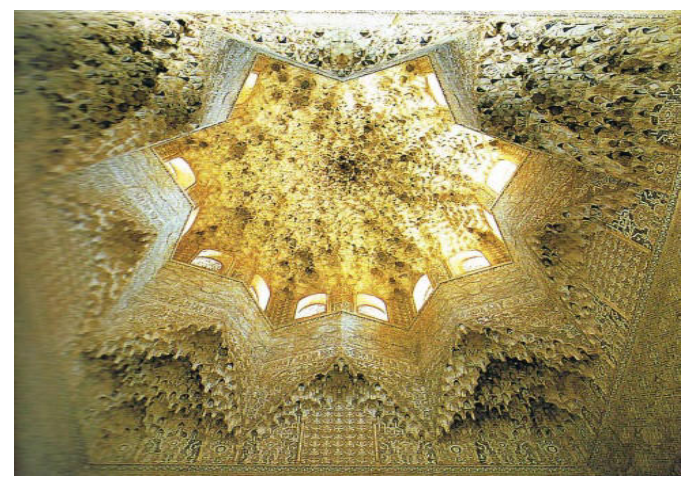

Figure (6): The ceiling of the Ibn Siraj Hall in the Alhambra Palace, which is a roof with an eight-pointed star dome. The light shines with an astonishing dwindling through Al-Muqarnas on the edge of the star

\section{The open courtyard (saucer)}

The Islamic architecture sought to benefit from natural energies to the fullest extent possible. It was designed according to standards that are suitable to the prevailing climatic conditions. As a result, different styles and methods have enabled Muslim architecture to benefit from these natural energies, the courtyard $^{8}$ has become a manifestation of Islamic architecture despite its use in various previous civilizations. ${ }^{9}$

It appears in the spaces of Islamic architecture that they receive light from an open dish, by the multiple doors and windows wide open throughout the long summer and if closed, the light remains the outlet of the colored and glazed arc light which is above most of the doors, even the outer sometimes. To reduce the intensity of the light and the dimensions of the walls of the house from the heat of direct sunlight, the interior was surrounded by open arched corridors open and no doors overlooking the inner courtyard, the rooms' doors and large windows look out through the hallways on the same plate.

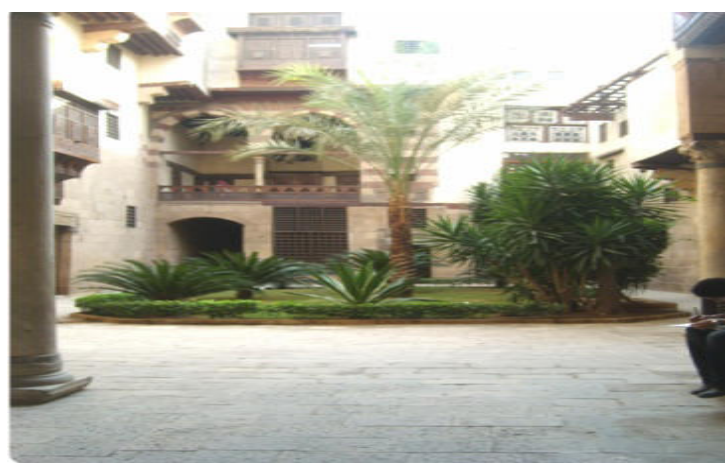

Figure (7): The inner courtyard of the house of the Suhaimi in Cairo, a picture showing an inner courtyard surrounded by rooms from the four sides and showing the view of these rooms on the courtyard through the openings overlooking it, which works to infiltrate the light through to the inside

In the cold areas where the roof is usually exposed, especially in public buildings, such as mosques, taverns, baths, schools, etc., the ceilings were made of different levels and shapes. They were vaulted, flat and

\footnotetext{
${ }^{8}$ The courtyard is defined in the Oxford Dictionary as "an open space surrounded by walls or buildings." The pathio is defined as an inner courtyard in Spanish or Spanish-American houses and is open to the sky, a Spanish word of origin and moved to English in 1827. This term is used interchangeably with the word ", And the word "courtyard" is usually used in the Arabic language for any open space in the house. As for the dish comes in the sense of the courtyard too, and the courtyard: the middle is a walled open area, see Waziri, Yahya: (2004). Islamic Architecture and the Environment, pp. 110-11. Policy Printing Kuwait, First Edition, Kuwait

${ }^{9}$ Waziri, Yahya, former source, p. 131.
} 
sloping, and windows were opened on the higher walls of the higher halls or domes.

\section{Openings (windows)}

Architectural openings in Islamic architecture can be classified into openings and windows that look outwards and others that overlook the inner courtyard. The openings on the ground floor are often more numerous than the first floor, "to allow much light to enter", ${ }^{10}$ and small openings usually limit the entry of solar radiation.

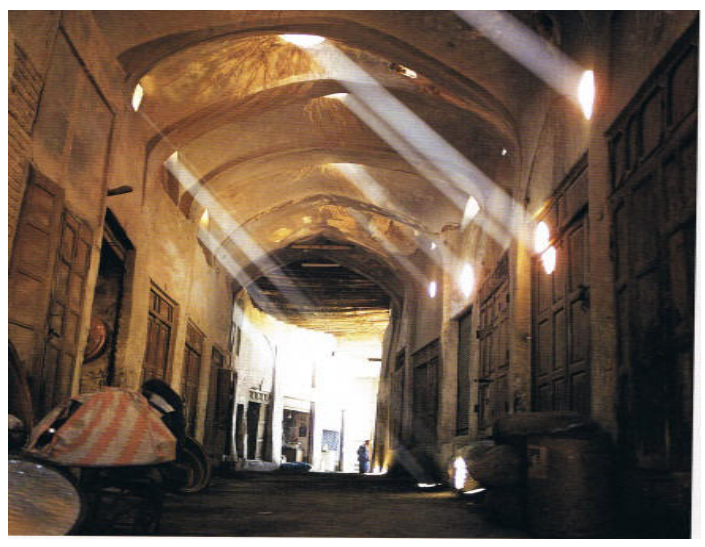

Figure (8): A market from Iran, showing the infiltration of light from overhead slots in beams of light to the lanes.

\section{Roof openings (Shakhshikha)}

Shakshikha was used in Islamic architecture as one of the types of ceilings ${ }^{11}$, It took the octagonal shape, in its four corners, is used to transform the square ceiling into an octagon in a flexible dimming that helps to spread the light better in the interior spaces. The light achieves functional and aesthetic dimensions when it reflects on the decoration and chandeliers on the top of the ceiling, perhaps this decline in the transition from octagonal to square shape contributed to the maximum use of light and distributed regularly in the vacuum, "rising from the top surface of the building, In the form of a small dome covering the hallway that is in the center of the hall, and the windows are placed on the perimeter of the neck "12, the use of Shakshikha in the Islamic architecture was associated with the concept of natural lighting, the light was scattered from the sun to the inside, through a central aperture, Shakshikha ${ }^{13}$ is very similar to the idea of using the openings in the neck of the dome, so that the light penetrates into the middle areas of the building, usually above the dura in Islamic houses and is sometimes covered with colored glass ${ }^{14}$.

\footnotetext{
${ }^{10}$ Rousan, A. (2009). Architectural and Structural Details of the Ancient Arab Islamic House, Vol,1., No,3., p. 67, National Library, Jordan

${ }^{11}$ Rizk, Hammad, previous source, p. 160.

12 Waziri, Yahya, former source, p.13

${ }^{13}$ Various forms of Shakshikha (roof openings) have emerged, some of which are eight shaped, such as those in the house of Suhaimi in Egypt, which is also in the Barqouq Mosque.

${ }^{14}$ Lamai, Saleh, (1984). Islamic Architectural Heritage in Egypt, First Edition, p. 69, Dar Al-Nahda Al-Arabiya for Printing and Publishing, Cairo
} 


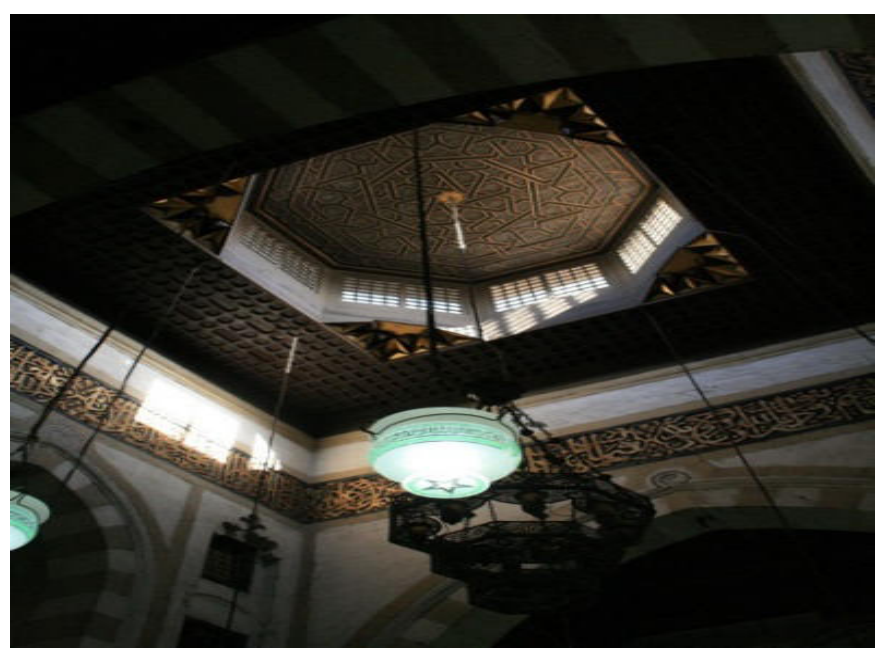

Figure (9): Eight busts, with a chandelier and hanging hanger, where natural lighting depends on the reflection of the surrounding walls with a lower light for the candlestick

\title{
4. The Lunar (sunshades)
}

\begin{abstract}
Luminaries were used in the Islamic architecture to introduce the dim moonlight from its interior to illuminate the interior spaces. These luminaries took different geometrical shapes and adopted the Muslim artist in his creations in different decorative formations to reflect their interior colors, See figure (10), the windows themselves were also used to cover these decorative openings with pieces of stained glass to introduce light in various shapes, Examples of these marble sunshades ${ }^{15}$ in the Umayyad Mosque ${ }^{16}$. In the Umayyad Mosque, two small domes appeared above each arch in the outer and inner corridors, in the wall of the Qiblah overlooking the plate are twenty doors, all of which are in the form of sunshades. The three lamps are connected with colored gilded lamps, reflecting light in the form of colored beams of light to the inner space. See Figure 11, The use of lumines is repeated in the domes "in the Islamic baths, where it opens" many kiln glazed with colored glass, takes several forms, usually mediated by a large star, when the sun shines through it to illuminate the bathroom, it looks like a real heavenly dome, and smaller domes provide light for the many showers. ${ }^{17}$ "
\end{abstract}

\footnotetext{
${ }^{15}$ The sunshade is a window or slot is decorated in the wall of the mosque is closed with a panel of marble or wood, and the term is also mentioned in the architecture of the Arab Maghreb corresponds to the (lunar) in the Islamic East, especially in Yemen, Which are originally small windows are usually at relatively high altitudes and their positions are determined in a technical way that overlaps with the decorative treatments of the room and cuts the plaster and adheres to the colored glass to make the threads of light and treatment to the room through which take a colorful body and aesthetic form, Especially when reflected on the pages of plaster embossed by the walls, and find them in the mosques are made above the niches, and dealing with the wealth of decorations and the color of the glass, see al-Twaini, Ali, a previous source, p.439

${ }^{16}$ Ghaleb, Abdul Rahim, previous source, p. 234.

${ }^{17}$ Qalji, Abdel Fattah, (1991).
} 


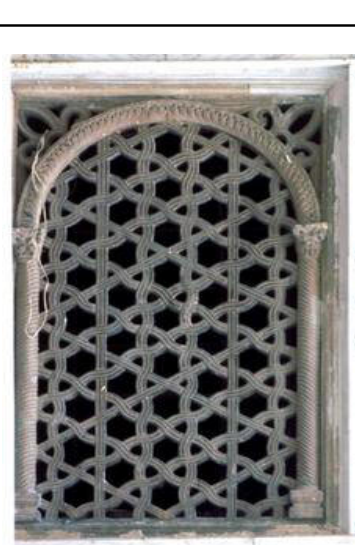

Figure (10): Lunar Umayyad Mosque in Syria

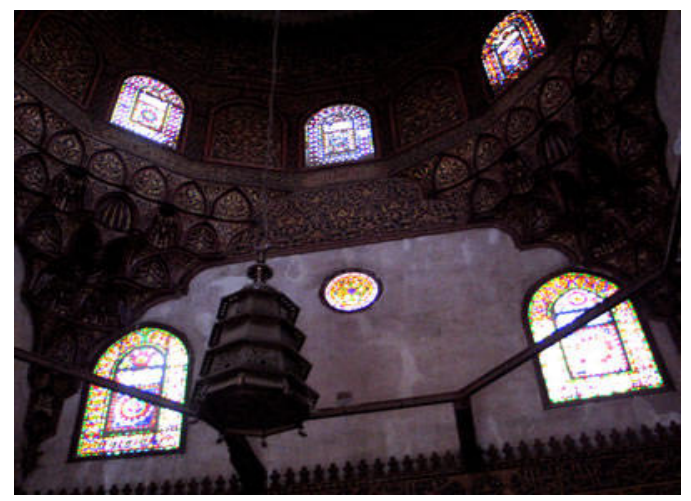

Figure (11): Al-Zaher Baybars School, Cairo, internal scene showing a group of Sunshades

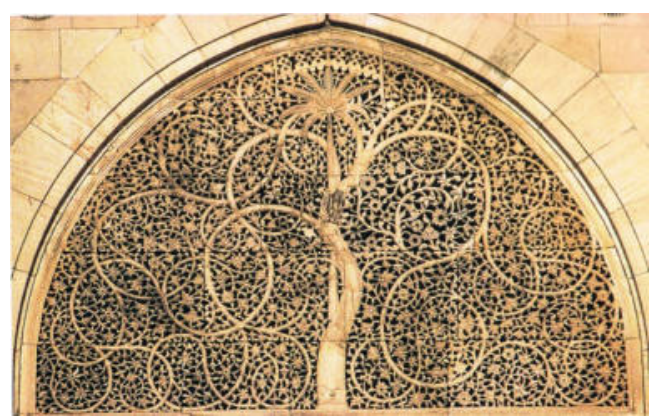

Figure (12): Qamariah, Sidi Saied Mosque, Ahad Abad, the lunar appearance from the outside with motifs and rotations in its body and secrets in which the light penetrates into the interior 


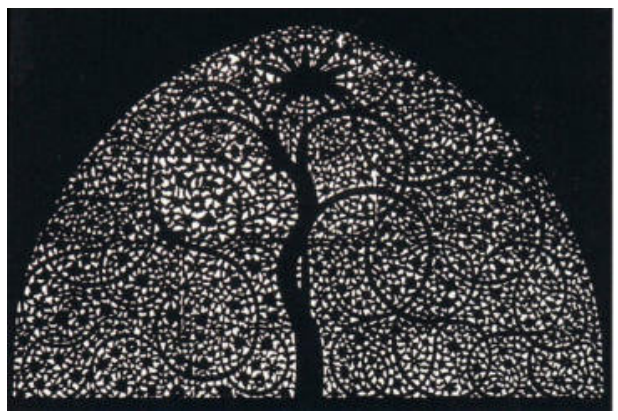

Figure (13): Qamaria, Sidi Saied Mosque, Ahmad Abad, Lunar appearance from the inside where infiltrates the light and appears in the white area, the black area is the lunar body

\section{Lighters (Al-Madawi)}

Al-Madawi was used as a small opening on the top of the wall or in the ceiling. It was blocked by a block of glass and used in the domes of the baths. It is shaped like a glazed opening. The bathroom consists of rooms with a curved roof, where Madawi opens ${ }^{18}$, See Figure 14, and the vaults and domes with holes covered by glass cutters to allow the passage of light without air, were used in the bathrooms as a method of coverage followed in the bathroom in general and has the advantages of increasing the mass of the vacuum required with the ratio of high steam ${ }^{19}$, in addition to the few high windows, the green, amber, transparent and blue glass bottles are used as construction material in the construction of the domes. They are also beautifully decorated, tightly bonded with mud, stones and roofing materials, allowing both sunlight and warm to be received at the same time $e^{20}$.

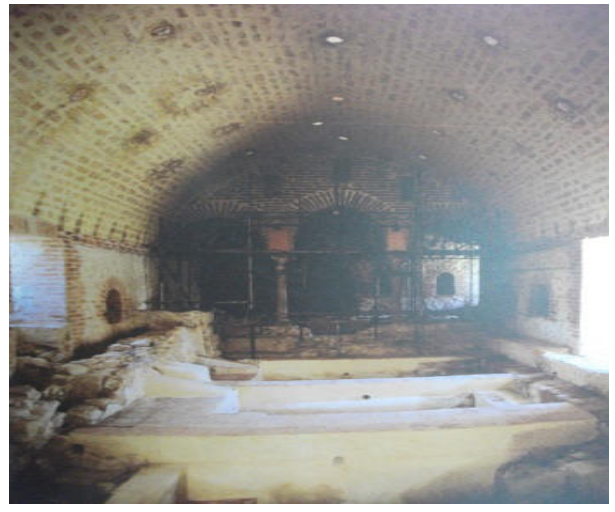

Figure (14): An interior view of an Arab-Persian bath (Normandy) 6th century AH / 12 AD, Italy. The openings on the top of the ceiling, which are specially designed for light penetration

It can be noted that al-Madawi was used as a light element and a functional component, it has been used in places where it is difficult to open windows in which it is relied on the lighting of the roof and the presence of al-Madawi in the bathrooms added to the functional color in terms of infiltration of lighting from these openings to the inside without the need to open windows in it. In addition, these windows have been decorated with

\footnotetext{
${ }^{18}$ Ghaleb, Abdul Rahim, previous source, p. 390.

${ }^{19}$ Supreme Council of Antiquities, (1995). Islamic Archaeological Studies, vol. V, Ministry of Culture, p. 238, Cairo

${ }^{20}$ Sheikh Abdul-Raouf Al-Manawi has defined the specifications of the bathrooms in light of the standard specifications of this age, as he defined in his book: "Integrity in the jurisprudence of legal and medical rulings." And that the bathrooms are "blocked and the windows have no energies, no gaps and no doors and that there is a lot of light, and that is only to take a glass of transparent glass and strengthen the radiation in it," see Azab, Khaled (2010). Islamic Architecture from China to Andalusia, 1, p. 39, Publisher, Dubai Cultural Journal, Dubai
} 
various glass formations of different colors, and light has been introduced into them by taking decorative forms and colors in accordance with these glazed openings (see Figs. $15+16$ ).

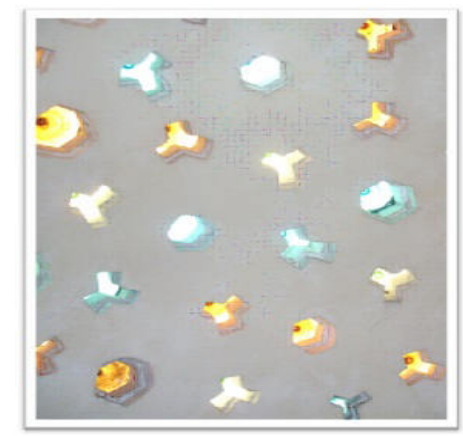

Figure (15): Lights from the House of Suhaimi in Cairo, and show the decorative shapes that spread the light in the form of colorful packages into the bathroom

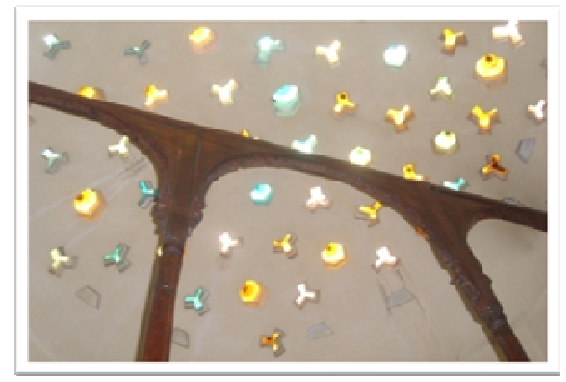

Figure (16): lights from the house of the Suhaimi in Cairo, and the decorative shapes that appear in the form of colorful beams of the ceiling of a dome in the ceiling of the bedroom

\section{The Mashrabiya}

In the past, the Mashrabiya was a prominent space with a slit hole where the small water tractor was placed to cool by the evaporation caused by the movement of air through the opening, now the name is called a slot with a wooden sling net made of small wooden bars with a circular section separated by specific and irregular distances in a delicate and complex architectural form.

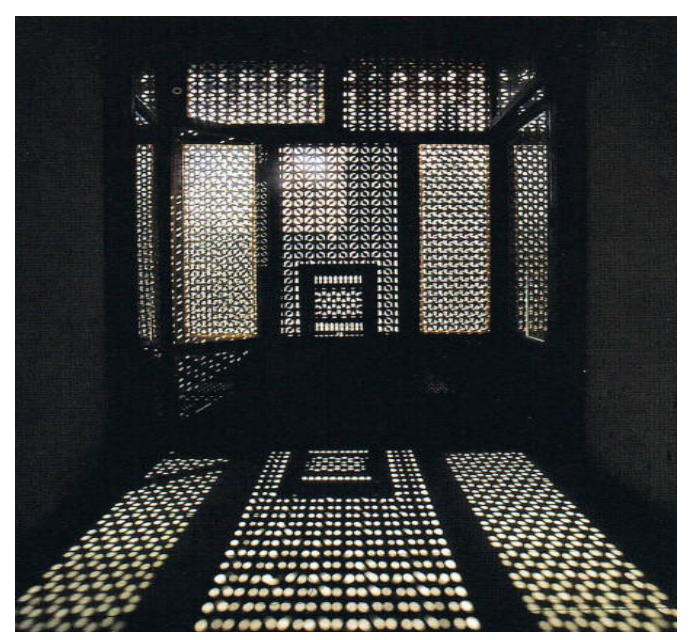

Figure (17): Mashrabia from Bashtak Palace, the light falling on the Mashrabiya from the inside shows the effect of the adjacent bars in the form of the light that penetrates inside 
Daytime light consists of any two elements: direct sunlight and reflected glare, and it is usually preferred to block the direct sunlight coming through the aperture because it warms the surfaces inside the room, thus raising the temperature of the atmosphere. The reflected glare does not heat the surfaces inside the room effectively but it causes discomfort to the eyesight.

\section{Analytical Study}

\section{a. Al Mashrabiya Slots - Arabesque:}

In the drawing for Al-Mashrabiya in figure $(18 \mathrm{~A}+\mathrm{B})$, the effect of the light falling on the Mashrabiya from an assumed angle shows that the light and shadow are placed on the body of the Mashrabiya, where the cylindrical body "reduces the intensity of the contrast resulting from light and darkness, Illuminated "21.

The different shapes and openings of Mashrabiyas have the greatest impact on the amount and shape of the light coming into the interior and the quality of the difference between the dimmer and glare. The distances between the bars of the Mashrabiya and the diameters of these bars determine the main light, through which the more the distance increased the amount of light inside and vice versa, In Figure (19), a detail of Mashrabia has been divided into two groups. In the first group, the amount of light is shown inside, which represents the negative area, See Figure (20), which is the area through which the light is not carried into the interior and represents the mass of wood and appear in the total area larger than the second group, which represents the vacuum is the positive area, (Figure 21), which is interspersed with light and less space than its predecessor, and most important in the penetration of light through which to the vacuum, where the form shows the spread of light and form a decorative in the vacuum, so that the light passing through these forms to the interior fades in the vacuum and spread and melt as a result of internal reflections of light. The interaction of light with Mashrabiya in a balanced and regular flow of light makes the interior appear as an aesthetic and artistic value, by taking advantage of the natural light as one of the manifestations that formed the light from the Mashrabiya.

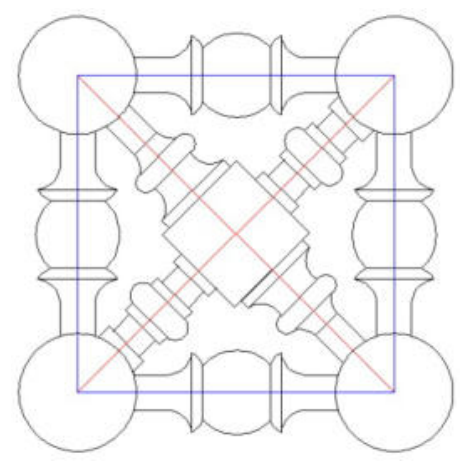

Figure (18a): Mashrabiya

\footnotetext{
${ }^{21}$ Fathi, Hassan, former source, p. 94.
} 


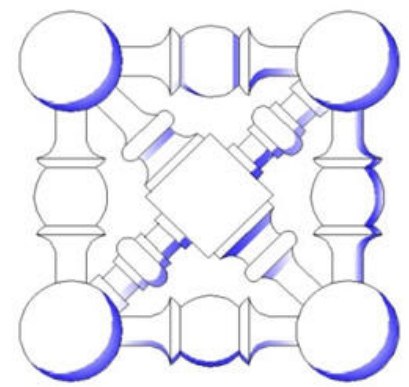

Figure (18b): Mashrabiya

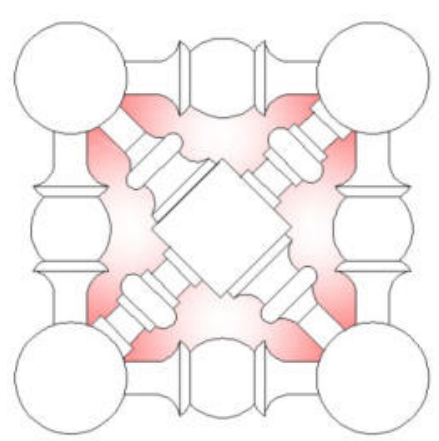

Figure (19): Mashrabiya

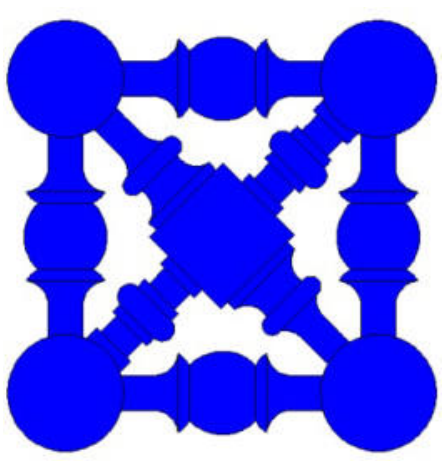

Figure (20): the negative area of Mashrabiya, which represents the form of light falling into the interior

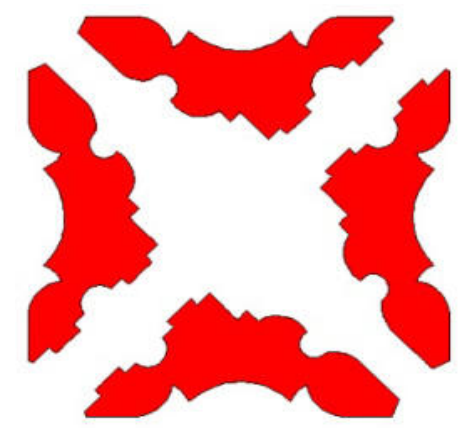

Figure (21): Positive area of Mashrabiya, which represents the form of light falling into the interior 


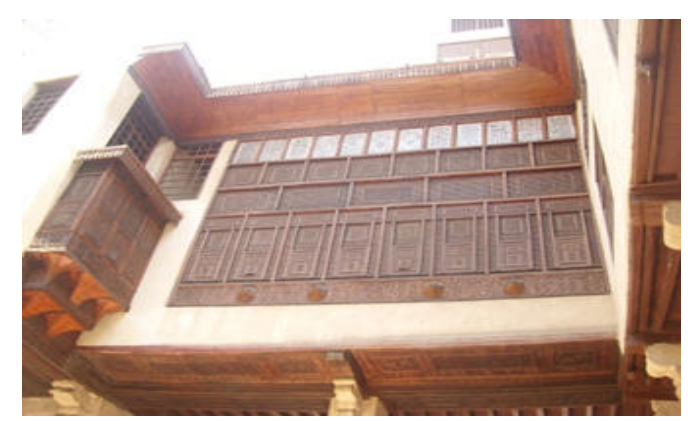

Figure (22): Mashrabia from the House of Suhaimi

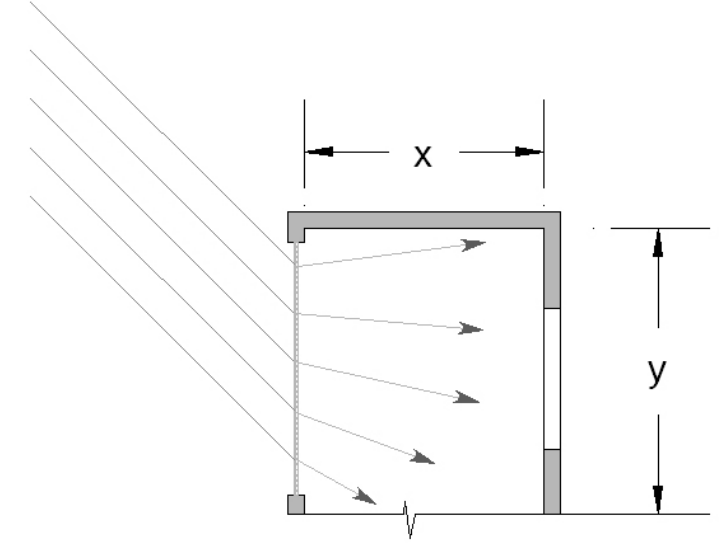

Figure (23): this section of the room in the house of the Suhaimi shows the size of the space relative to the size of Mashrabiya, the use of Mashrabiya with the size of the wall of the room gave a greater spread of light as the side of the Mashrabiya is almost equal to the height of the room which is $y$ and that $y$ (i.e. room height) Increases slightly from (room width), this convergence between height and width enables sunlight to reach deeper places in the vacuum

\section{b. Sunshades and Lunarities}

The difference of light in the space is affected by the natural light and the intensity of light and the windows of natural light, the sun is characterized by a decorative element with a variety of forms and decorative variations, in view of the figure $(24+25)$, the idea in the work of these sunshades due to an aesthetic origin where these sunshades decorated the walls of Islamic buildings, it is also possible to be divided into two groups, the areas of blocking the light which are the negative, see figure (26) represented by the mass of stone or plaster and the positive one, see figure (27) which represent the spaces and shape of the light passing through.

The presence of these sunshades in high places facilitates the spread of light and its reflections within the rooms, the Suns' harmony with Light appears as an aesthetic and functional element with its architectural function, thus creating a series of harmonious and balanced shapes between separate parts of each other in the sunshade in aesthetic formations in the formation of light. 


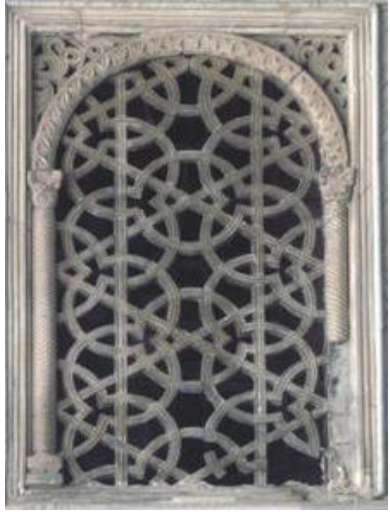

Figure (24): Sunshade from the Umayyad Mosque in Damascus, showing the spaces and decorative tattoos that led the light to the interior on the forms of decorative geometric

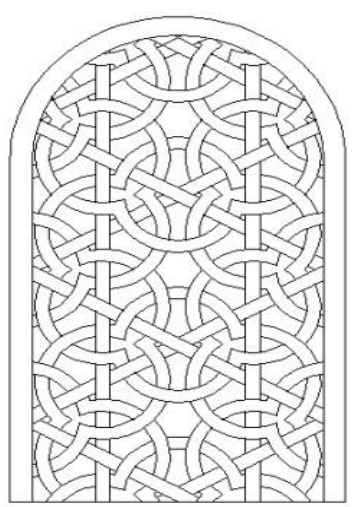

Figure (25): Sunshade from the Umayyad Mosque in Damascus, decorative analysis of the sun

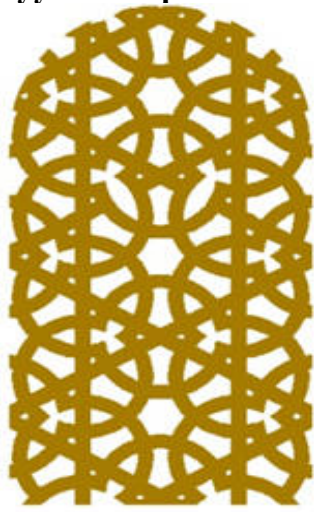

Figure (26): Sunshade of the Umayyad Mosque in Damascus, the negative area of the light, which is the area of the light that passes to the interior, which is the decorative unit repeated from the stone mass 


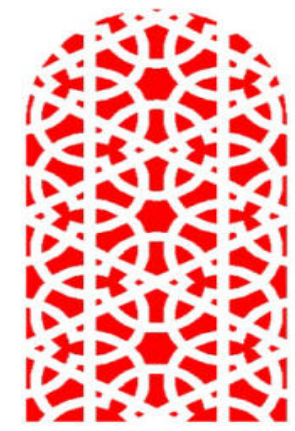

Figure (27): Sunshade of the Umayyad Mosque in Damascus, the positive area of the light, the areas through which the light passes through to the interior, where the red color shows the shape of the light in decorative form

\section{c. The relationship of the courtyard to the distribution of natural light}

The architectural details of the Islamic vacuum construction show great care in the functional relations of the vacuum and the size of the openings and their proportions to achieve and provide a light consistent with the function of vacuum, for example, in Al-Suhaimi's house there are design patterns for different openings designed to provide suitable and appropriate lighting within the vacuum, When analyzing and comparing the internal spaces of the interior, it appears that the architectural style in dealing with the interior spaces expresses its commitment and ability to provide conditions for the interior lighting, in the analysis of the interior courtyards shows that the first courtyard, which is distributed around the rooms is located in the middle of the house and overlooking the upper halls and surrounded by the windows covered with Mashrabiya, thus, the light penetrating into the courtyard had an impact on the perception of the interior spaces surrounding the courtyard on the four sides, where it showed the effects of light levels in terms of the apparent perception of the interior space.

"The extension of the courtyard to the longitudinal direction of the building enabled us to take advantage of the sunlight that penetrates the courtyard most of the day, and the polygon layout of the building in the shape of a rectangular shape is best suited to store the minimum heat in the summer". ${ }^{22}$

Figure 28 shows a diagram showing the inner courtyard and the movement of the rooms around these courtyards. This helped to penetrate the sun's rays into these spaces through the openings and gaps in the dwelling and to form the largest role in the use of natural lighting. This shows that the longest side of the general plan Head to the east and west, the most exposed to the sun during daylight hours.

The variety of these methods through a variety of architectural treatments in the natural lighting is one of the most important things that formed the appearance of Islamic architecture and worked on the superiority of functional and aesthetic aspects of Islamic architecture, in Figure 28, the courtyard appears with the letter A + B, and the location of the inscription appears in the letter D, which has worked to bring light to the areas that the sun does not reach from the site of the house, it has been shown that the area of the two courtyards is equal to about $30 \%$ of the building area (about one-third), in addition to the concentration of these courtyard around the rooms and the opening of windows from the rooms on them, it turned out that these yards are distributed to most of the rooms around them, see Figure (29).

The movement of the sun in the house of Suhaimi and the angles of the fall of the sun works to stabilize the light in these spaces, may be due to the fact that the sun in Cairo in summer is very hot, so builders tried to break the sun by using the courtyard surrounded by high-rise buildings while relying on other architectural elements to deliver the sun's reflections to interior spaces.

\footnotetext{
${ }^{22}$ Victor Volgyay, the leading scientist in the field of solar radiation and ecology, concluded by using his own mathematical equations that square construction is not necessarily the most appropriate form, but that the rectangular architectural forms along the north-south axis are less effective during winter and summer and less effectively than the square shapes, therefore the most appropriate shape is the rectangle in the east-west direction.
} 


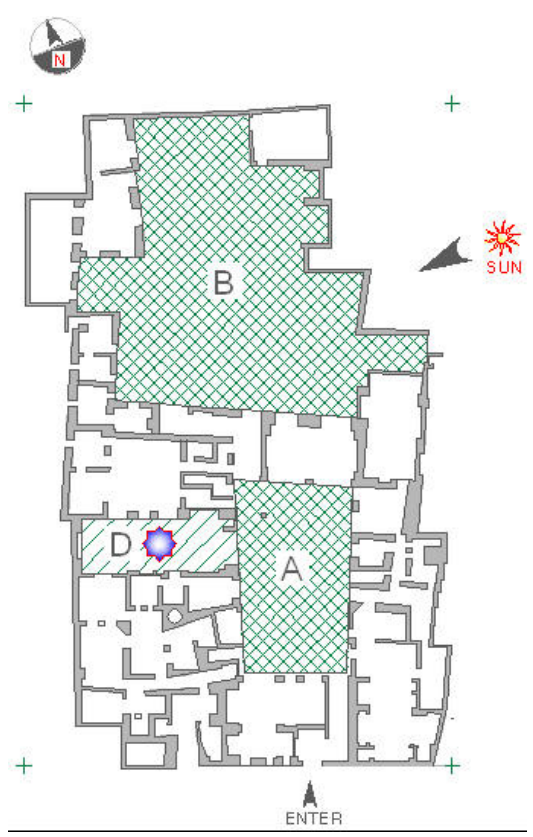

Figure 28: Al-Suhaimi house plan in Cairo (1648-1796). It is clear that the spaces and interior designs are in addition to the places where the ceiling lighting falls. These spaces are located in places that help to reach the deep places inside the house

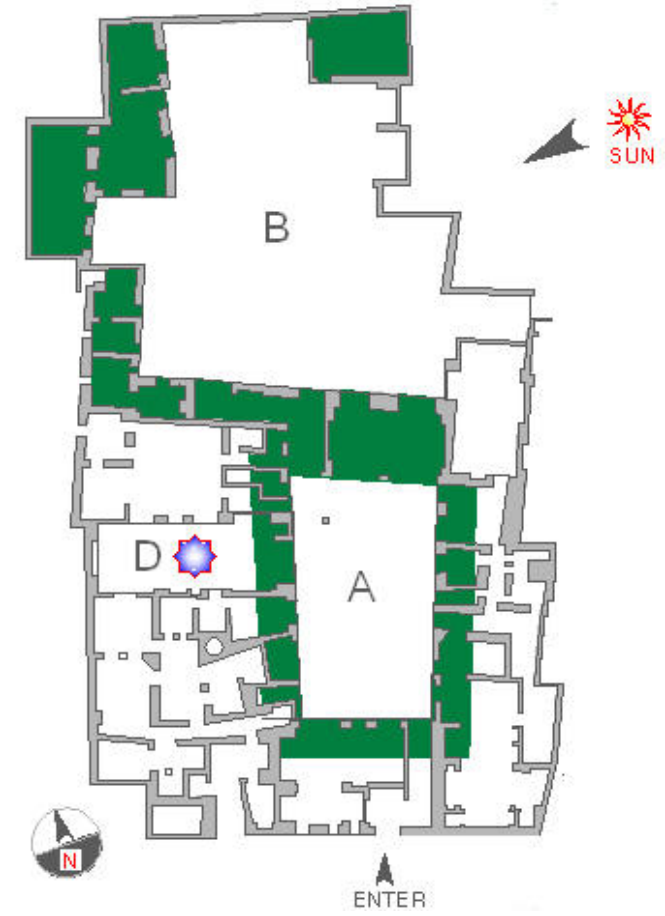

Figure (29): The areas of natural light effect appear in green and are the spaces around the two yards

Figure (30) shows the extent of the influence of the central courtyard on the penetration of light into the interior, the passage of the rays and their reflections show the arrival of the light into deeper areas of the vacuum, based on the reflected light from the courtyard and the surrounding surfaces. 


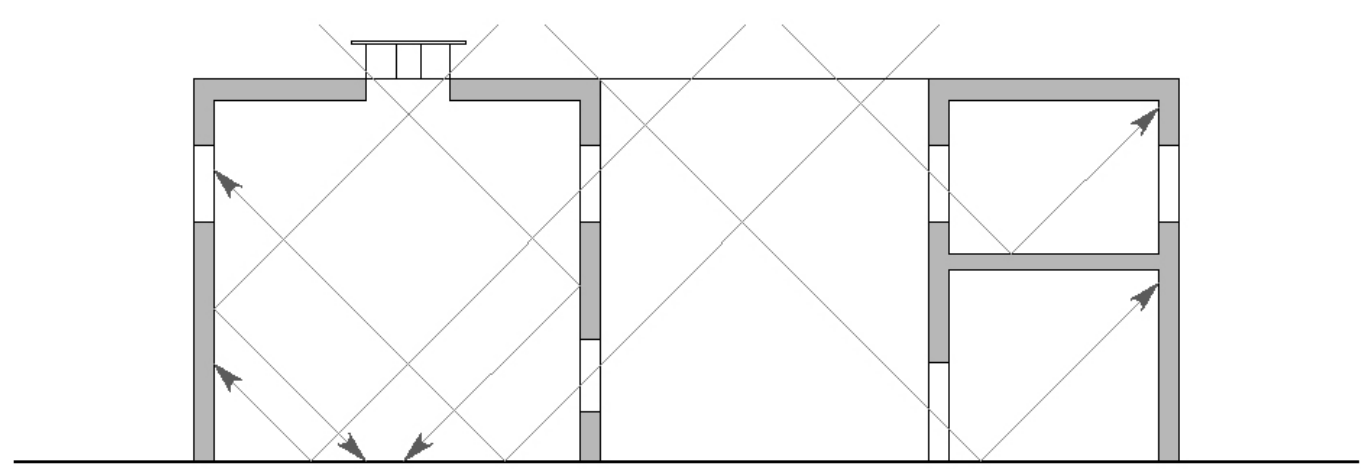

Figure (30): A section in the courtyard number (A) shows the direction of the fall of the rays of natural daylight and spread in the yard and passing and reflected in the interior

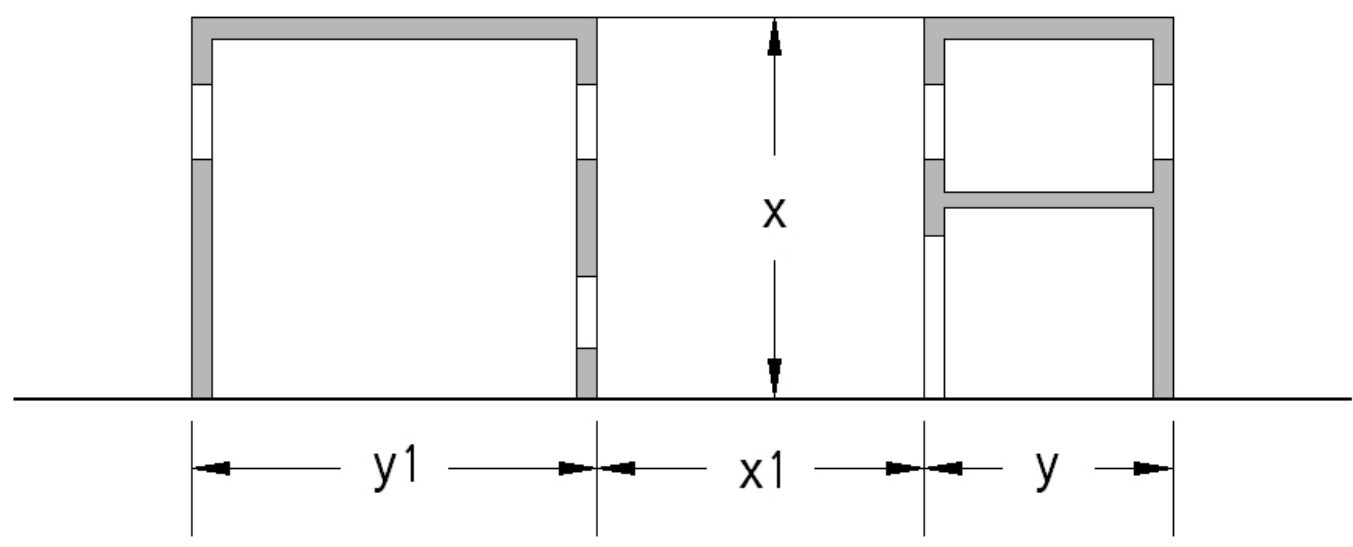

Figure (31): The courtyard appears in the central region where $x+x 1$ is equal to the width and height of the courtyard, which is approximately one-third of the width of the building. This space enables the light to reach most parts of the inner courtyard

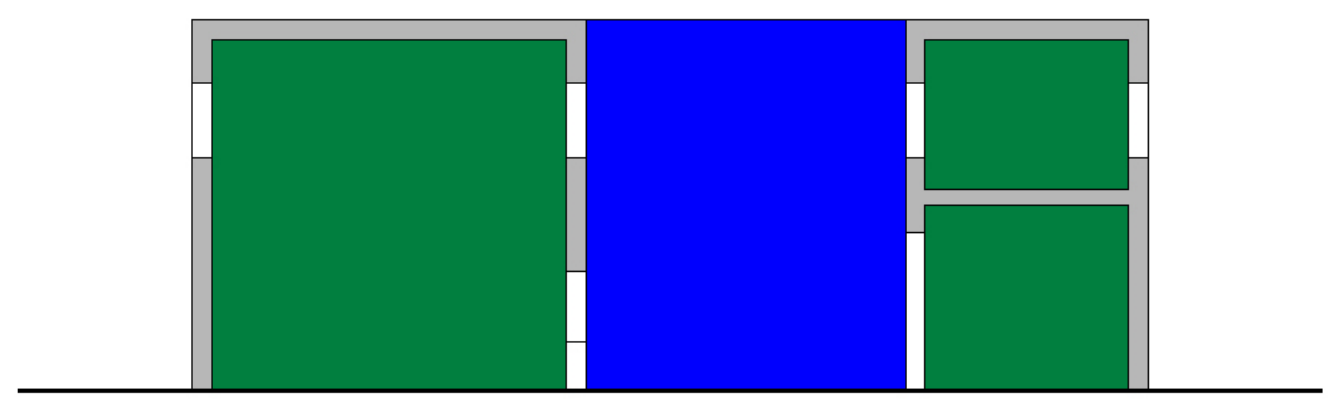

Figure (32): This section shows the negative area of the building, which represents the space dedicated to the courtyard, which appears in blue as the presence of this space is the middle of two other areas in green converge in size with the space in blue

\section{Conclusion}

The function of light has differed in Islamic art. It does not express it, it does not emerge through shadow, or it is similar to the manifestations of nature through it and does not specify distances near or far, it establishes a relationship of balanced clarity between light as one of the manifestations of natural light and the 
architectural elements of the general architectural form, whether these elements are a window with light through the empty tangles of the metal or the hollow plaster or cone wood or the hollow stone that forms the surface of the window, or through the exposed open-air dish to the vaulted or flat-paneled hallways that illuminate the open-air home.

The emergence of different types of natural and industrial lighting in Islamic architecture did not differ in structure and philosophy of art from other Islamic arts, the nature of unity, repetition, symmetry and abstraction are traits that have stuck to the structure of these patterns, whether natural or industrial, which influenced the formation of light in the vacuum, where the light arrived in the interior part of the philosophy of Islamic decoration in making the light infiltrator takes a spiritual and material dimension in the vacuum.

\section{Results}

1. Islamic interior design was not separated by inspiration (light) as a manifestation of basic nature, but created a close, stable, balanced, harmonious relationship with man and light.

2. Islamic architecture is an aesthetic way to confirm the light, discover it and show it aesthetically. Light has become an aesthetic way to highlight the architecture, its elements, its system, its aesthetic laws and its reflection on the visual movement such as continuity, balance and architectural rhythm.

3. That the light works to reduce the weight of the raw material and contribute to its transparency such as iron, stone and wood, especially the aesthetic elements hollow that allow light to enter and increase the absorption and the establishment of mutual relations with it through the overlap of light to fill the empty areas of raw material and specific lines of straight and curved and square and round and triangular, wood, stone, plaster, marble and iron.

4. The industrial patterns in lighting contributed to the delivery of light to the lower areas inside the buildings, especially in areas that are not light enough during the day, and worked to illuminate these levels at night.

5. The natural lighting patterns have been affected by light levels in terms of the apparent perception of interior space. The high levels of light have increased the size of the interior space, and the presence of high openings has helped define areas with special events such as sitting or pathways in space by relying on the natural light reflected from the rays of the sun with high levels and openings.

6. It was clear that the interior space was affected by the size and shape of the perforated openings in terms of the amount of luminance passing inward, as it is clear that the space of the vacuum has received an organized lighting in the distribution of the amount of light coming from the top of the central point of the ceiling, the high side vents, which worked to control the amount of light passing into the interior and organizing it in beams of light permeate the internal space.

\section{References}

Al-Tuwaini, A.(2005). The Islamic Peoples Architecture Dictionary, First Edition, Damascus. 8 - 10 - Supreme Council of Antiquities, (1995). Islamic Archaeological Studies, Volume V, Ministry of Culture, Cairo

Azab, Khaled (2010). Islamic Architecture from China to Andalusia, Vol, 1., Publisher, Dubai Cultural Magazine, Dubai

Farouqi, I. (1983), Islam and Architecture, Contemporary Muslim Magazine, No. 34, Beirut

Fathi, H. (1988). Natural Environments and Traditional Architecture, Arab Foundation for Studies and 
Publishing, First Edition, Beirut

Ghaleb, A. (1988). Encyclopedia of Islamic Architecture, Issue,1., p. 57, Arabic Printing Press, Beirut

Hammad, R. (1996) Daylight and Industrial Lighting in Architecture, Arab Center, First Edition, Amman, Jordan

Lamai, S. (1984). Islamic Architectural Heritage in Egypt, First Edition, Dar Al-Nahda Al-Arabiya for Printing and Publishing, Cairo

Melnik, V. (2008). The treasures of Damascene architecture, Vol,1., Dar Al Sharq for printing and publishing, Damascus

Monroe, Th. (1972). Evolution in the Arts, translated by Mohamed Ali Abu Durra et al, Vol,1., p.42, Egyptian Book Authority, Cairo

Nasr, H. (2004). Principles of Islamic Architecture and Contemporary Urban Problems, Articles in the Islamic Arts, Jordan

Rousan, A. (2009). Architectural and construction details in the old Arab-Islamic house, Vol,1., N 3., National Library, Jordan

Salfiti, M.(2004). Environmental Architecture, Vol,1., Dar Gabes, Beirut.

Saqr, I. (2003). Islamic Arts, Vol,1., Dar Majdalawi, Amman

Waziri, Y. (2004). Islamic Architecture and Environment, Al-Siyasa Press Kuwait, First Edition, Kuwait

Zaki, H. (1956). Atlas of Decorative Arts and Islamic Painting, Vol,I., Cairo University Press, Cairo 